\title{
Influence of Hyperproteinemia on Insect Innate Immune Function of the Circulatory System in Bombyx mori
}

\author{
Yong-Feng Wang $1,2,{ }^{\dagger}$, Guang Wang ${ }^{1,2,+}$, Jiang-Lan $\mathrm{Li}^{1,2}{ }^{\text {, Ya-Xin } \mathrm{Qu}}{ }^{1}$, Xin-Yin Liang ${ }^{1,2}{ }^{,}$Xue-Dong Chen ${ }^{1,2}$, \\ Yang-Hu Sima ${ }^{1,2}$ and Shi-Qing $\mathrm{Xu}{ }^{1,2, *}$ \\ 1 School of Biology and Basic Medical Sciences, Medical College, Soochow University, Suzhou 215123, China; \\ yfwang1993@suda.edu.cn (Y.-F.W.); 20194021007@stu.suda.edu.cn (G.W.); \\ 20194221011@stu.suda.edu.cn (J.-L.L.); 20174221004@stu.suda.edu.cn (Y.-X.Q.); \\ 20184221025@stu.suda.edu.cn (X.-Y.L.); chenxd@suda.edu.cn (X.-D.C.); simyh@suda.edu.cn (Y.-H.S.) \\ 2 Institute of Agricultural Biotechnology \& Ecology (IABE), Soochow University, Suzhou 215123, China \\ * Correspondence: szsqxu@suda.edu.cn; Tel.: +86-512-65880185 \\ + These authors contributed equally to this work.
}

Citation: Wang, Y.-F.; Wang, G.; Li, J.-L.; Qu, Y.-X.; Liang, X.-Y.; Chen, X.-D.; Sima, Y.-H.; Xu, S.-Q. Influence of Hyperproteinemia on Insect Innate Immune Function of the Circulatory System in Bombyx mori. Biology 2021, 10, 112. https://doi.org/10.3390/ biology10020112

Academic Editor: Klaus H. Hoffmann Received: 24 December 2020

Accepted: 27 January 2021

Published: 3 February 2021

Publisher's Note: MDPI stays neutral with regard to jurisdictional claims in published maps and institutional affiliations.

Copyright: (C) 2021 by the authors. Licensee MDPI, Basel, Switzerland. This article is an open access article distributed under the terms and conditions of the Creative Commons Attribution (CC BY) license (https:/ / creativecommons.org/licenses/by/ $4.0 /)$.
Simple Summary: Hyperproteinemia, a condition of elevated protein levels in the blood, is associated with a diverse range of human and animal diseases. However, there is no reliable hyperproteinemia disease models or modeling methods in mammal or other organisms, and the effect of hyperproteinemia on immunity is still unknown. Our work succeeded in constructing an animal model of hyperproteinemia with no primary disease effects and a controllable plasma protein concentration (PPC) in an invertebrate model organism, Bombyx mori. Our work confirmed that high PPC enhances hemolymph phagocytosis via a rapid increase in granulocytes and inhibited hemolymph melanization due to inhibition of the prophenoloxidase (PPO) signaling pathway, and also upregulated the gene expression of antimicrobial peptides via activating the Toll and Imd pathways in NF-kB signaling, and showed an inconsistent antibacterial activity for Gram-positive and Gram-negative bacteria. Our results show that high PPC had multiple significant effects on the innate immune function of the silkworm circulatory system and is expected to be improved by endocrine hormones. Our work explores the pathogenesis of hyperproteinemia in an invertebrate model, and expands the scope for silkworm biomedical applications, even use for a potential drug development platform.

Abstract: Metabolic disorders of the circulatory system of animals (e.g., hyperglycemia and hyperlipidemia) can significantly affect immune function; however, since there is currently no reliable animal model for hyperproteinemia, its effects on immunity remain unclear. In this study, we established an animal model for hyperproteinemia in an invertebrate silkworm model, with a controllable plasma protein concentration (PPC) and no primary disease effects. We evaluated the influence of hyperproteinemia on innate immunity. The results showed that high PPC enhanced hemolymph phagocytosis via inducing a rapid increase in granulocytes. Moreover, while oenocytoids increased, the plasmacytes quickly dwindled. High PPC inhibited hemolymph melanization due to decreased phenoloxidase (PO) activity in the hemolymph via inhibiting the expression of the prophenoloxidaseencoding genes, PPO1 and PPO2. High PPC upregulated the gene expression of antimicrobial peptides via differential activation of the Toll and Imd signaling pathways associated with NF- $\mathrm{B}$ signaling, followed by an induction of inconsistent antibacterial activity towards Gram-positive and Gram-negative bacteria in an animal model of high PPC. Therefore, high PPC has multiple significant effects on the innate immune function of the silkworm circulatory system.

Keywords: Bombyx mori; innate immunity; melanization; NF-kB signaling; plasma protein concentration (PPC) 


\section{Introduction}

Hyperproteinemia is a metabolic disease, which has recently been reported to be associated with an abnormally elevated plasma protein concentration (PPC) as a clinical symptom [1-5]. This hyperproteinemia is commonly exhibited in many important clinical diseases in humans, as well as other mammals (e.g., multiple myeloma $[4,6]$, nephropathy [7-10], hepatopathy [11,12], and pathogen infections [2,13]). Hyperproteinemia also appears in metabolic acidosis and even clinical plasma therapy or intravenous immunoglobulin therapy [9,14-16]. A clinical study from the Benghazi Medical Center showed that out of 99 diagnosed cases of multiple myeloma, 30\% developed hyperproteinemia ( $>9 \mathrm{gm} / \mathrm{dL}$ ) [4]. A total of 51 dogs with canine leishmaniosis (CanL) caused by Leishmania infantum were studied at the School of Veterinary Medicine of the Autonomous University of Barcelona, and clinical hyperproteinemia was found to be as high as $52.9 \%$ [2].

Metabolic disorders of the circulatory system are typically characterized by the presence of abnormally increased or decreased metabolites in the circulating blood, which can cause many clinical diseases (e.g., hyperglycemia [17], hyperlipidemia [18], hypercholesterolemia $[19,20]$, and hyperuricemia [21]). It is particularly interesting that patients with hyperproteinemia generally display metabolic changes (e.g., abnormal blood glucose and blood lipid levels) [4,5], and there is a significant change in the proportion of circulating blood cells $[8,22]$. These findings imply that hyperproteinemia has complex effects on the circulatory system.

Previous studies have shown that a metabolic balance disorder of the circulatory system affects the normal function of blood cells and is closely related to changes in blood immunity [23-25]. Hyperglycemia and metabolic disorders may directly promote pathological changes of normal cell functions through modifications of $\beta$-N-acetylglucosamine (O-GlcNAc) [26]. In the hyperglycemia microenvironment, high glucose protects pancreatic cancer cells from natural killer cell (NK)-mediated killing by inhibiting the expression of MHC class I chain-related protein A/B (MICA/B), and promotes the immune escape of cancer cells [27].

In patients with hyperlipidemia, Toll-like receptor (TLR) 2 appears to activate the innate immune signaling cascade in platelets by binding to endogenous lipid peroxidation ligands [28]. Hyperlipidemia can induce an increase in T helper cell 17 (Th17) secreting immune proteins in the spleen, which results in an enhanced immune response to modified lipids and aortic inflammation [29]. Hypercholesterolemia can induce T cell expansion, which plays a key role in the adaptive immune response in humanized immunized mice, and upregulates the expression of transforming growth factor beta 1 (TGFb1) in the liver $[29,30]$. Hypercholesterolemia enhances TLR signaling, activates inflammasomes, and promotes inflammation [31].

Invertebrate model animals, such as Bombyx mori and Drosophila, have sensitive innate immune systems, including humoral (hemolymph) and cellular immunity, but no adaptive immune system [32-35]. When the silkworm can resist pathogen invasion, the prophenoloxidase cascade activated in oenocytoids (Oen) by pathogens and other stimuli converts prophenoloxidase (PPO) into active phenoloxidase (PO). PO further hydroxylates monophenolase (MPO) and oxidizes BIS-phenoloxidase, producing a large amount of quinone intermediates to polymerize and form melanin. These melanins then cooperate with cytotoxic quinone intermediates for deposition around invading pathogens, followed by pathogen isolation and killing [36-38]. At the same time, granulocytes (Gra) will accumulate in the hemolymph and engulf pathogens. Furthermore, the Toll and Imd pathways in insects and other animal cells are stimulated by microorganisms [32,39-41]. Moreover, signaling through these pathways further activate the NF-KB-like transcription factors, Dif/Dorsal, and Relish. These transcription factors are then transferred into the nucleus to induce antibacterial AMPs and the transcription of other related genes. Using Drosophila as a model, NF- $\mathrm{KB}$ signaling regulation of innate immunity through the Toll and Imd pathways has been widely studied and confirmed [42,43]. Among them, Gram-positive bacteria primarily activate the Toll pathway, whereas the Imd pathway mainly responds to 
immune stimulation with Gram-negative bacteria $[35,44]$. There are also bacterial infections that simultaneously activate Toll and Imd, which induce different reactions.

Currently, the effect of hyperproteinemia on immunity remains unclear due to that it is difficult to distinguish hyperproteinemia from primary disease or infection, and there is no reliable animal model in mammals or fruit fly [45-48]. In addition, hyperproteinemia is often complicated by abnormal blood sugar and blood lipid levels in these patients. In our previous research, we created an animal model of hyperproteinemia (AM) with no primary disease using an invertebrate model animal [45,46], Bombyx mori, in which hyperproteinemia could be generated by controlling plasma protein concentration (PPC) levels. This model revealed that high PPC has complex effects on metabolic tissue fat body remodeling and gonad development $[45,46]$. This suggests that in the open blood circulation system of insects, high PPC may have a direct impact on innate immunity. Hence, we constructed an animal model for hyperproteinemia in silkworm and investigated the effect of hyperproteinemia on innate immune function of the circulatory system in this model.

\section{Materials and Methods}

\subsection{Animal Model}

The Dazao strain of Bombyx mori was used as the animal model in the current study. The experimental process to create a hyperproteinemia animal model (AM) was performed as previously described in $[45,46]$. The larvae were reared on fresh mulberry (Morus) leaves at $25^{\circ} \mathrm{C}$ with a $12 \mathrm{~h}$ light $/ 12 \mathrm{~h}$ dark photoperiod until they grew into mature larvae, namely the wandering stage, at which point they were ready to enter the subsequent spinning stage and complete their pupa metamorphosis development. The fibroin in silk glands (SG) (accounts for 30\% of the body weight) was then prevented from being released outside the larva by covering the spinneret with a low-melting-point paraffin wax. The fibroin in the glandular cavity is also released into the circulatory system in the subsequent metamorphosis during the physiological degradation of the SG, and then we remodeled a high PPC silkworm (AM). Whereas silkworms in control group (CK) remained untreated. $(\mathrm{AM}+20 \mathrm{E})$, the larvae of $\mathrm{AM}$ were rescued by injecting $4 \mu \mathrm{g}$ of $20 \mathrm{E}$ $(10 \mu \mathrm{L}$ per larva, $0.4 \mu \mathrm{g} / \mu \mathrm{L})$ (Sigma-Aldrich, St. Louis, MO, USA) at $24 \mathrm{~h}$ after modeling. Then, the larvae were kept under natural conditions as the CK group until they grew into adult moths.

The hemolymph and fat bodies were collected from the silkworms at the indicated time points after modeling $(48,96$, and $192 \mathrm{~h})$, when PPC is in the rising stage, peak stage, and late stage of the platform, respectively. Each tissue (or hemolymph) sample was collected from three female individuals, and each sample was measured three times.

\subsection{Fat Body Collection and Transcriptome Sequencing}

At 48 and $96 \mathrm{~h}$ after modeling, fat bodies were removed and collected from each larva in $0.7 \% \mathrm{NaCl}$. Total RNA was extracted from fat bodies using the RNAiso Plus Kit (TaKaRa, Dalian, China), chloroform, isopropyl alcohol, $75 \%$ ethanol, and $\mathrm{DEPC}_{2} \mathrm{O}$, following the manufacturer's protocol. Transcript library construction and sequencing were performed using Illumina Novaseq 6000 platform by Majorbio (Shanghai, China). Each fat body sample was collected from three female individuals, and each sample was measured three times. The samples were named as CK48h_1/2/3, AM48h_1/2/3, CK96h_1/2/3, AM96h_1/2/3, respectively.

\subsection{Transcriptome Assembly, Annotation, and Differential Analysis}

After sequencing, the original sequencing data were quality controlled to obtain highquality control data (clean data) to ensure the accuracy of subsequent analysis results. The genome and gene model annotation referenced the silkworm database (http:/ / metazoa. ensembl.org/Bombyx_mori/Info/Index). The expression levels of the gene and new transcripts were assessed by Transcripts Per Million reads (TPM). These differentially 
expressed genes were subjected to Kyoto Encyclopedia of Genes and Genomes (KEGG) (http:/ / www.genome.jp/kegg/) and Gene Ontology (GO) (http://www.geneontology. org) databases for functional annotation and enrichment analysis. KEGG pathways and GO terms were defined as significantly enriched with $p$-adjust $<0.05$.

\subsection{Real-Time Polymerase Chain Reaction Analysis}

The level of gene transcripts in the hemocytes and fat bodies was analyzed via quantitative real-time polymerase chain reaction (qRT-PCR). Rp49 was used as a reference gene. qRT-PCR was performed in a $20 \mu \mathrm{L}$ reaction solution using an ABI StepOnePlus ${ }^{\mathrm{TM}}$ real-time PCR system (Ambion, Foster City, CA, USA). The total RNA was extracted by traditional methods for qRT-PCR, and qRT-PCR was performed as described previously [46] using the primers listed in Table S1.

Hemocyte and fat bodies were removed from the silkworms at the indicated time after modeling $(48,96$, and $192 \mathrm{~h}$ ). Each tissue (or hemolymph) sample was collected from three female individuals, and each sample was measured three times.

\subsection{Determination of Phenoloxidase (PO) Activity}

Hemolymph was collected from the silkworms at the indicated times after modeling, and hemolymph samples were centrifuged under $4{ }^{\circ} \mathrm{C}(12,000 \times g$ for $5 \mathrm{~min})$. In a 96 -well plate, $280 \mu \mathrm{L}$ PBS was added to each well and preheated at $28^{\circ} \mathrm{C}$ for $30 \mathrm{~min}$. Next, $10 \mu \mathrm{L}$ hemolymph and $10 \mu \mathrm{L} 0.01 \mathrm{mM}$ L-Dopa was added in sequence. An OD value under A490 $\mathrm{nm}$ was continuously measured with a microplate reader $(20 \mathrm{~min}$ period, time interval $2 \mathrm{~min}$, reaction temperature $28^{\circ} \mathrm{C}$ ). The calculation process was performed as described previously [49]. The PO activity was measured in three female individuals, and each individual was measured three times.

\subsection{Melanization Measurement}

At $48 \mathrm{~h}$ after modeling, $50 \mu \mathrm{L}$ of hemolymph from female silkworms was collected and the changes in hemolymph melanization were observed until one group was completely black at room temperature $\left(25^{\circ} \mathrm{C}\right)$. The observations were repeated in three silkworms $(n=3)$.

\subsection{Hemocyte Counting}

A $5 \mu \mathrm{L}$ supersaturated solution of phenylthiourea was added to each $200 \mu \mathrm{L}$ hemolymph sample. Next, $10 \mu \mathrm{L}$ of the sample was collected and added to the blood count plate. The type and number of hemocytes was counted and observed under a fluorescence microscope (Olympus BX51, Tokyo, Japan) ( $n=3$ samples).

\subsection{Antibacterial Activity}

A total of $20 \mu \mathrm{L}$ of bacteria, Escherichia coli (E. coli) and Staphylococcus aureus (S. aureus), was added to $4 \mathrm{~mL}$ of LB liquid culture, respectively. The bacteria were shaken cultured to mid-log phase, then adjusted to OD570 $=0.2$ with the culture medium, as the bacterial solution used for measurement. The hemolymph was incubated in a metal bath at $100{ }^{\circ} \mathrm{C}$ for $5 \mathrm{~min}$, and then centrifuged under $4{ }^{\circ} \mathrm{C}$ at $4000 \times \mathrm{g}$ at $4{ }^{\circ} \mathrm{C}$ for $5 \mathrm{~min}$ to collect the supernatant plasma. In a 96-well plate, $80 \mu \mathrm{L}$ bacterial solution and $20 \mu \mathrm{L}$ plasma was added to each well and shaken cultured $(220 \mathrm{r} / \mathrm{min})$ at $37^{\circ} \mathrm{C}$. An OD value under A570 nm as a proliferation parameter of the bacteria was continuously measured using a microplate reader (time interval of $60 \mathrm{~min}$ ). The measurements were repeated for six wells $(n=6)$, and Kanamycin was added as a positive control. The experimental process was performed as described in [50].

\subsection{Data Analysis}

Statistical analysis of data was performed using GraphPad Prism 8 software and the significance was analyzed using the Holm-Sidak method for multiple t-tests at one per 
row. Unless otherwise stated, all data were presented as the mean $\pm \operatorname{SEM}(n=3) .{ }^{*} p<0.05$; ${ }^{* *} p<0.01 ;{ }^{* * *} p<0.001 ;$ n.s., no significant difference between the two groups.

\section{Results}

\subsection{High PPC Induces Hemocyte Phagocytosis}

There are five types of hemocytes in the silkworm hemolymph, including prohemocyte (Pro), plasmacyte (Pla), granulocyte (Gra), spherulocyte (Sph), and oenocytoids (Oen) (Figure 1A). Among these hemocytes, the immune function of Gra is phagocytosis, whereas Pla and Oen produce phenoloxidase to encapsulate foreign matter.

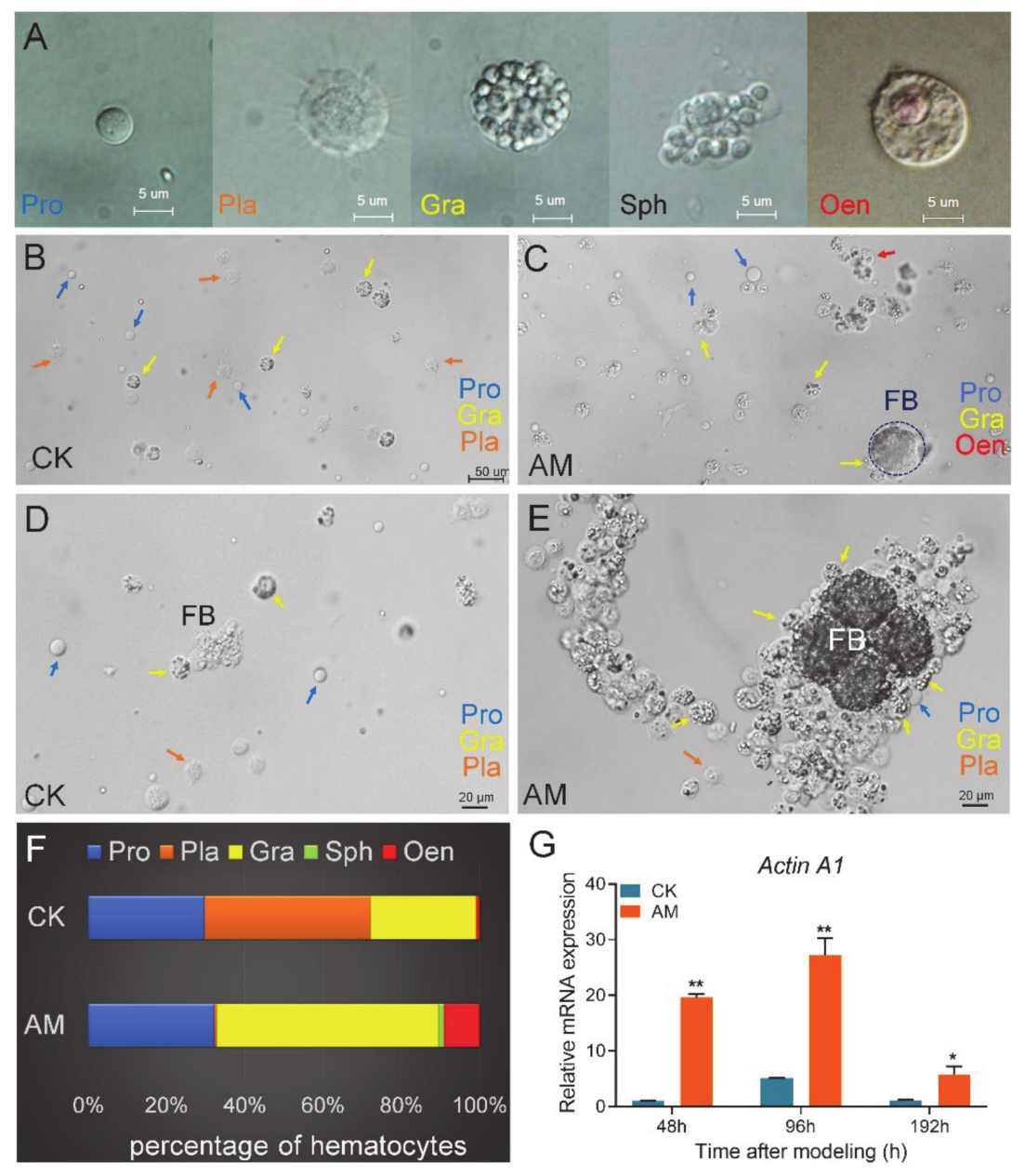

Figure 1. Effect of high plasma protein concentration (PPC) on hemocytes in hemolymph of silkworm. (A) Types of hemocytes in hemolymph of the silkworm pupae. Pro, prohemocyte. Pla, plasmacyte. Gra, granulocyte. Sph, spherulocyte. Oen, oenocytoid. (B,C) The state and classification of hemocytes status in CK group (B) and AM group (C) at $48 \mathrm{~h}$ after modeling. (D,E) A large number of granulocytes gather around the free fat body in AM group (E) compared to the CK group (D) at $48 \mathrm{~h}$ after modeling. (F) The proportion of hemocytes at $48 \mathrm{~h}$ after modeling. (G) The relative mRNA levels of phagocytosisrelated marker gene Actin A1 in hemocytes from silkworm at 48-192 h after modeling. ${ }^{*} p<0.05$; ** $p<0.01$. Mean \pm SEM. $n=3$.

The number of Gra and Oen and the ratio of both among the total hemocytes increased rapidly in the AM group at $48 \mathrm{~h}$ after modeling. The number of Pla and the ratio in the total hemocytes were seriously reduced (Figure 1B-F). At 48, 96, and $192 \mathrm{~h}$ after modeling, the proportion of Gra increased from $26.9 \%, 28.6 \%$, and $43.5 \%$ in the CK group to $56.6 \%, 54.5 \%$, and $86.3 \%$, respectively, which nearly doubled (Figure S1). The proportion of Oen increased from $0.9 \%$ and $2.4 \%$ in the CK group to $9.1 \%$ and $12.9 \%$ at 48 and $96 \mathrm{~h}$, respectively, but 
dropped from $8.7 \%$ in the CK group to $2.4 \%$ at $192 \mathrm{~h}$. The most significant reduction was observed for Pla, as its proportion was reduced by $96.4 \%$ and $69.1 \%$ compared with the CK group at 48 and 96 h, respectively. By 192 h, there was almost no Pla in the AM group, and the proportion of Pla in the CK group was as high as $25.2 \%$ (Figure S1). In the hemolymph at $48 \mathrm{~h}$ after modeling, it was clearly observed that the increased Gra in the AM group enhanced the envelopment and phagocytosis to the remodeling tissue fat body (FB) (Figure 1C,E). Phagocytosis is a receptor-mediated, actin-dependent endocytosis [51,52]. We investigated the mRNA level of phagocytosis-related marker gene Actin A1. The relative mRNA level of Actin A1 was significantly upregulated in hemocytes compared with CK after modeling (Figure 1G). These results suggest that high PPC may affect the cellular immunity of Bombyx mori.

\subsection{High PPC Affects the Expression of Innate Immune-Related Genes}

To evaluate the impact of high PPC on the silkworm innate immune system, transcriptomic sequencing was performed using FB, an important tissue related to anabolism and immunity. The GO analysis showed that at $96 \mathrm{~h}$ after modeling, the level of gene transcription of biological process, cellular components, molecular function, and other processes exhibited significant changes, including 21 immune stress-related genes and 19 immune system process genes directly related to immune function (Figure 2A).

The transcriptome immunoassays showed that at $96 \mathrm{~h}$ after modeling, antimicrobial peptides (AMP) genes (e.g., CECA, LEB1/2, BGIBMGA013108, and BGIBMGA014285) were significantly upregulated compared with the CK group (Figure $2 \mathrm{~B}$ ). When comparing $96 \mathrm{~h}$ to $48 \mathrm{~h}$ after modeling, the number of immune-related genes that changed significantly increased from 10 to 21, 18 of which were newly emerged genes (Figure 2C). The heatmap shows that 21 immune-related genes exhibited significant changes, except for the downregulation of BGIBMGA006716 and BGIBMGA007400, the remaining 19 genes are all significantly upregulated (Figure 2D).

Further KEGG analysis revealed that high PPC significantly induced the expression of AMP genes in innate immune response. Moreover, genes in the Toll and Imd signaling pathway were involved in the regulation of the expression of AMPs in NF- $\mathrm{kB}$ signaling, which exhibited significant changes in the level of transcription (Table S2). In addition, high PPC induced changes in silkworm innate immunity.

The level of AMP mRNA in the FB was measured (Figure 3), and it was found that at 48, 96, and $192 \mathrm{~h}$ after modeling, the level of Moricin, Defensin, Lebocin, and CecropinA mRNA expression was significantly upregulated in the AM group, in which Defensin was upregulated to the greatest extent (Figure 3C-F). At the same time, the level of Attacin and Gloverin mRNA expression was significantly downregulated compared with CK at $96 \mathrm{~h}$ after modeling; however, a significant upregulation or no difference was observed between 48 and $96 \mathrm{~h}$ (Figure 3A,B). The differences in AMP transcription in the AM group suggest that it may be related to different upstream signaling pathways that regulate AMP expression. It is important to note that in both the CK group and AM group, the level of AMP mRNA in the FB first increased then decreased during the 48-192 $\mathrm{h}$ period (Figure 3). This finding is highly consistent with the PPC changes in the AM group reported in our previous modeling experiments. This implies that the level of AMP mRNA in the FB is affected by the level of PPC. 
A

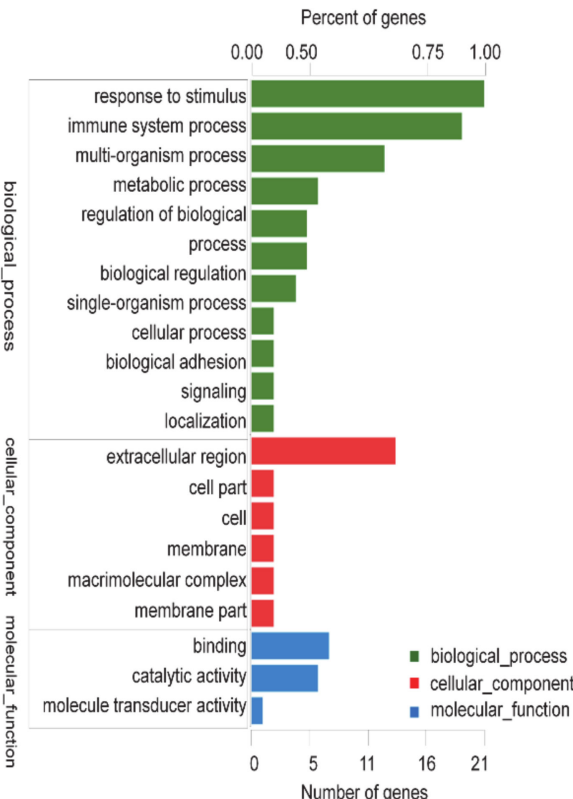

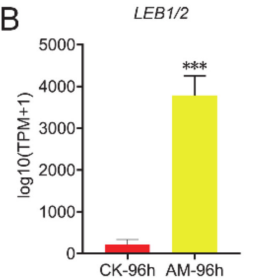

BGIBMGA013108
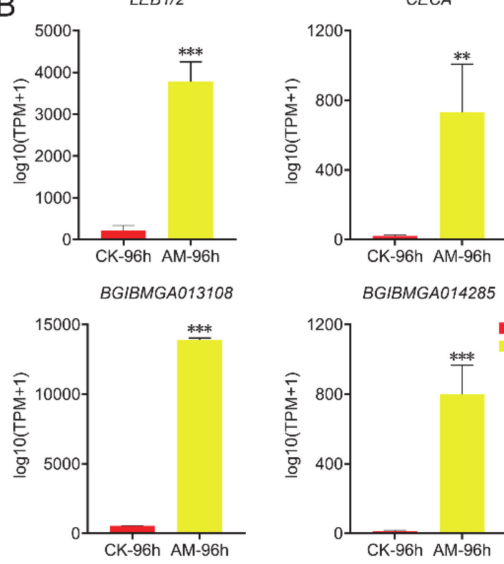

BGIBMGA014285

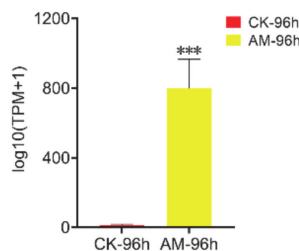

C

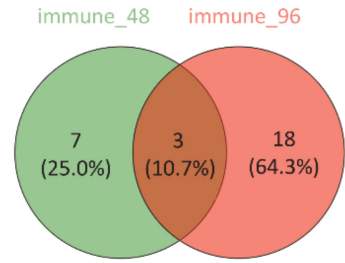

Heatmap

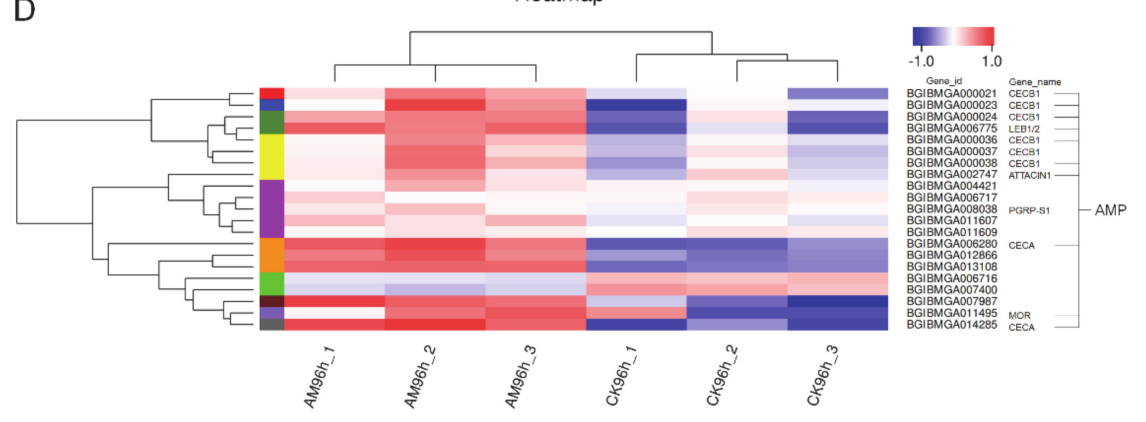

Figure 2. Transcriptome analysis of immune-related genes. (A) GO annotations analysis at $96 \mathrm{~h}$ after modeling. 'Number of genes' and 'Percentage of gene' refer to the number of differentially expressed genes involved in biological processes and its proportion in the total number of differentially expressed genes, respectively. (B) The expression of immune-related genes changed significantly at $96 \mathrm{~h}$ after modeling. (C) Venn diagram, the number of immune-related genes that changed significantly at 48 and $96 \mathrm{~h}$ after modeling. (D) Heatmap, differences in expression of immune-related genes that significantly changed at $96 \mathrm{~h}$ after modeling. Most of the genes belong to AMP genes, and others have not been annotated. Each column in (D) represents a sample, and each row represents a gene. The color represents the normalized expression value of the gene in each sample. Red represents the higher expression level of the gene in the sample, and blue represents the lower expression level. The number label under the color bar on the upper right represents the specific expression level change trend. On the left is the tree diagram of gene clustering and the module diagram of sub-clusters, and on the right is the name of the gene. ${ }^{* *} p<0.01 ;{ }^{* * *} p<0.001 . n=3$. 

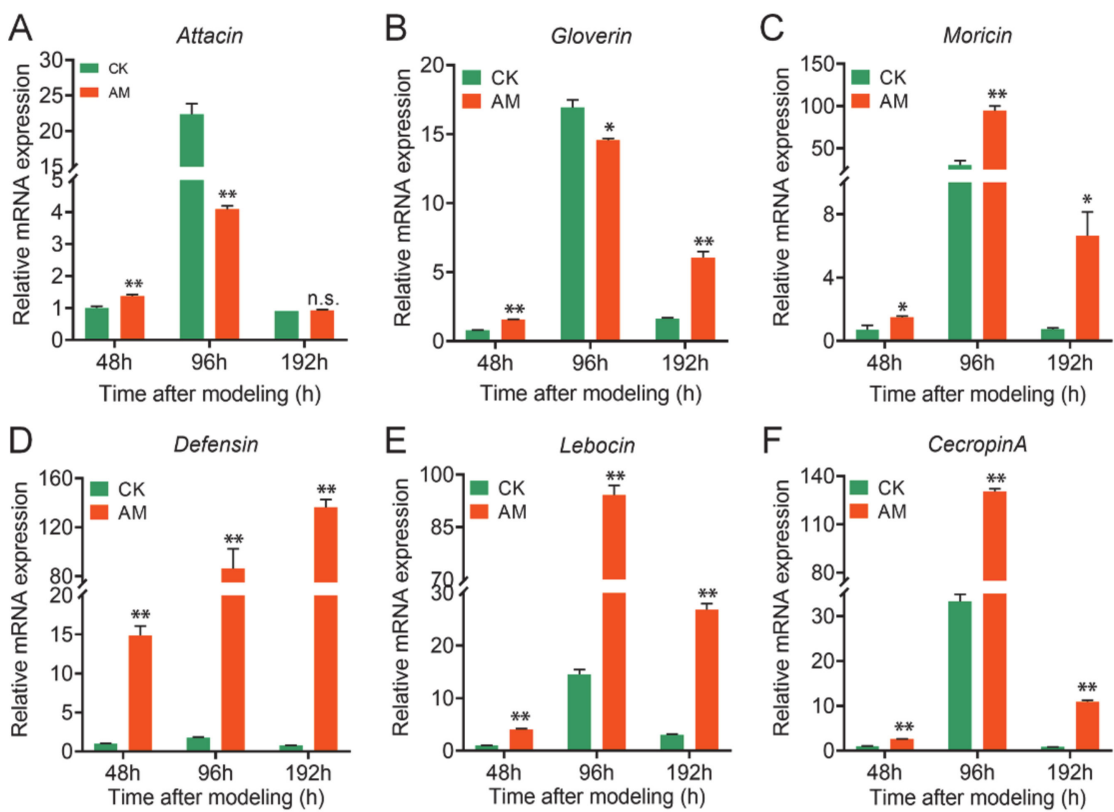

Figure 3. High PPC induced AMPs upregulation in fat body. (A-F) mRNA levels of AMP genes in fat body from silkworm at $48-192 \mathrm{~h}$ after modeling. ${ }^{*} p<0.05$; ${ }^{* *} p<0.01$; n.s., no significant difference between the two groups. Mean \pm SEM. $n=3$.

\subsection{High PPC Affects Hemolymph Antibacterial Activity}

To further examine the impact of high PPC on the innate immune system, we further focused on the silkworm hemolymph, which exerts the most extensive innate immunity, and investigated the humoral immune response to high PPC.

The antibacterial activity testing results using growth rate as an indicator (Figures $4 \mathrm{~A}$ and S2) showed that the plasma of the AM group had a significant effect on the antibacterial activity of the Gram-negative bacteria, Escherichia coli (E. coli). Although there was no statistical difference between the AM group and the CK group at the early time point of $48 \mathrm{~h}$ after modeling, the growth rate of E. coli in the AM group was significantly lower than that of the CK group at 96 and $192 \mathrm{~h}$ after cocultivation for more than $2 \mathrm{~h}$ (Figures $4 \mathrm{~A}$ and S2B).

However, the Gram-positive bacteria, Staphylococcus aureus (S. aureus), exhibited different results. At $48 \mathrm{~h}$ after modeling, the growth rate of the AM group was slower than that of the CK group during 1-3 $\mathrm{h}$ of coculture. However, no difference was observed between the 4-6 h coculture and the CK group (Figure S2C). In the 96 and $192 \mathrm{~h}$ investigations, the growth rate of the AM group did not differ from that of the CK group within $3 \mathrm{~h}$ of cocultivation. The continued culture was significantly faster than that of the CK group (Figures 4A and S2D). This finding showed that high PPC induced an increase in the antibacterial activity of silkworm hemolymph against $E$. coli, but inhibited the antibacterial activity against $S$. aureus.

The level of AMP mRNA, the main humoral immune substance in silkworm hemocytes, was further determined. It was found that at 48, 96, and $192 \mathrm{~h}$ after modeling, the level of Attacin, Gloverin, Moricin, Defensin, Lebocin, and CecropinA mRNA was significantly upregulated, except for the downregulation of Gloverin gene transcription at $96 \mathrm{~h}$. Moreover, the Defensin and CecropinA genes were upregulated hundreds to thousands of times compared with that of the CK group (Figure 4B).

It is important to note that the degree of induction of AMPs expression in hemocytes of the AM group was much higher than that in the FB as a whole (Figures 3 and 4). This further confirmed that high PPC may have a major impact on the innate immunity of hemocytes by inducing the expression of AMPs. In the results presented in Figures 3 and 4, the differences in the transcription level of the AMP members in the AM group suggest 
that high PPC may be related to differences in the effects of different upstream signaling pathways, which regulate the expression of AMP members.
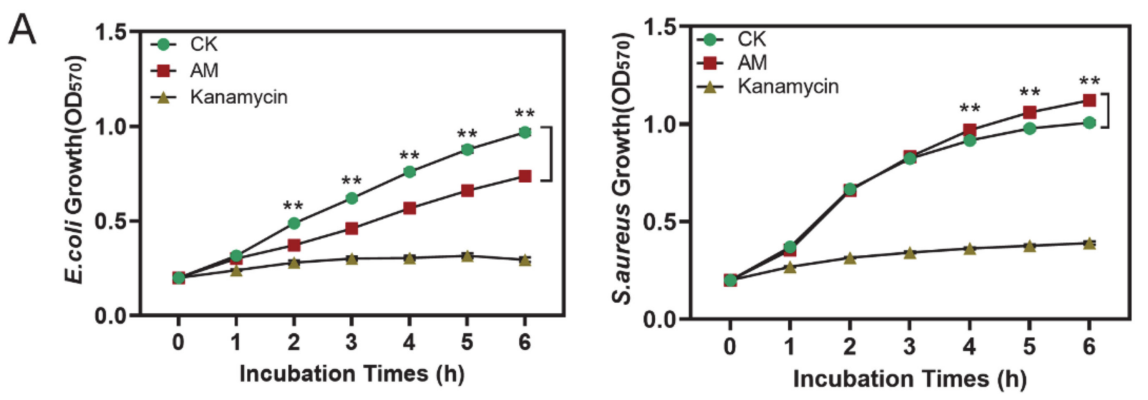

B
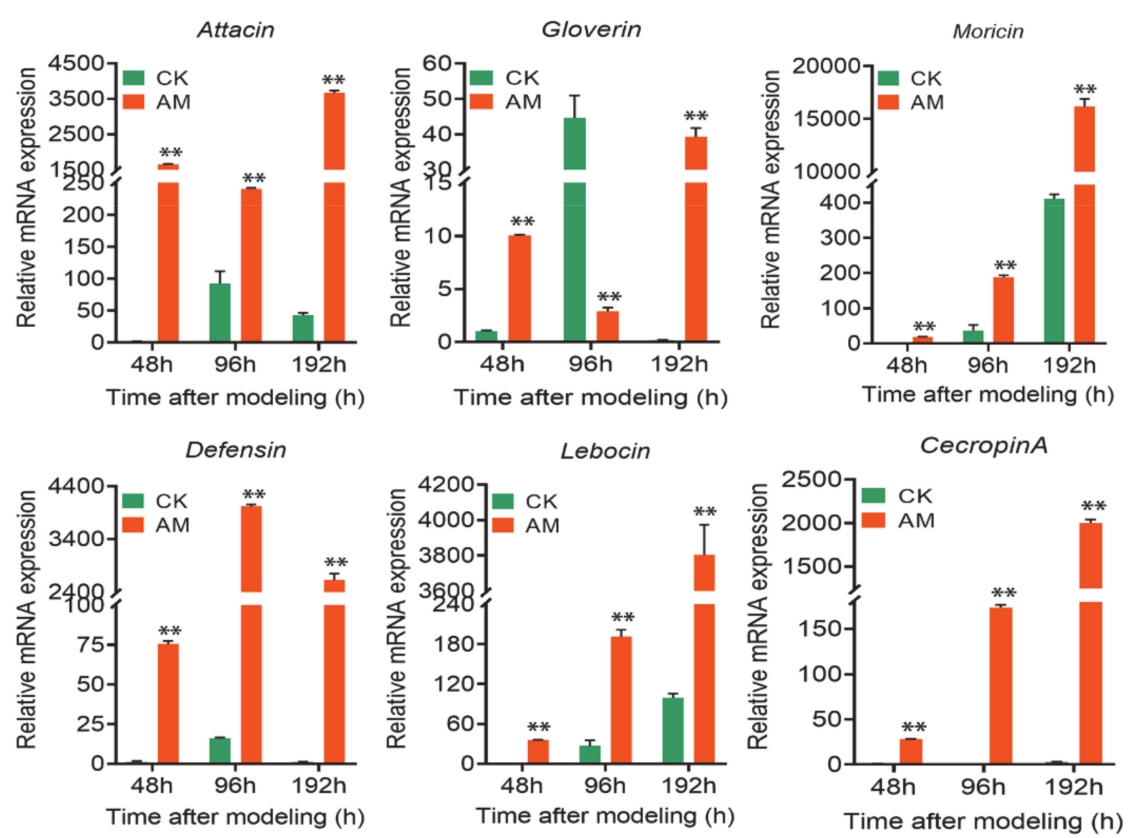

Figure 4. High PPC affected the antibacterial activity in hemolymph. (A) Antibacterial activity of high PPC silkworm cell-free hemolymph. The hemolymph of the silkworm was removed for heat treatment at $192 \mathrm{~h}$ after modeling, and the supernatant was cocultured with Escherichia coli (E. coli) and Staphylococcus aureus (S. aureus), and the growth of E. coli (left) and S. aureus (right) was investigated. (B) The mRNA levels of AMP genes in hemocytes from silkworm at 48-192 h after modeling. ${ }^{* *} p<0.01$. Mean \pm SEM. $n=3$.

\subsection{AMP Expression is Regulated by NF- $\mathrm{B} B$ Signaling}

We further investigated the changes in transcription levels of key NF- $\mathrm{KB}$ signaling molecules involved in regulating AMP expression in the hemocytes (Figures 5 and S3). The key member gene mRNA levels of the Toll pathway showed that spaetzle-1 (Spz-1), Toll-4, Myd88, and Dorsal in the hemocytes exhibited significant changes after modeling. During the three time points of investigation, with the exception of a continuous increase in the level of Dorsal mRNA, the level of transcription of the other three genes in the CK group all showed changes that first increased and subsequently decreased. Unlike the CK group, the mRNA levels of these four genes in the AM group were rapidly downregulated from 48 to $192 \mathrm{~h}$ after modeling (Figure 5). From the perspective of gene transcription, the mRNA levels of these four genes in the AM group were significantly upregulated dozens of times more than CK, early at $48 \mathrm{~h}$ after modeling. Among these, the Dorsal transcription level of the Toll signal was upregulated by 250-fold. However, in the late time point of $192 \mathrm{~h}$ after modeling, the level of Spz-1, Myd88, and Dorsal transcription in the AM group were 
all downregulated to levels lower than that of CK. Moreover, Toll-4 was also significantly downregulated to a level close to that of the CK group (Figure 5D).
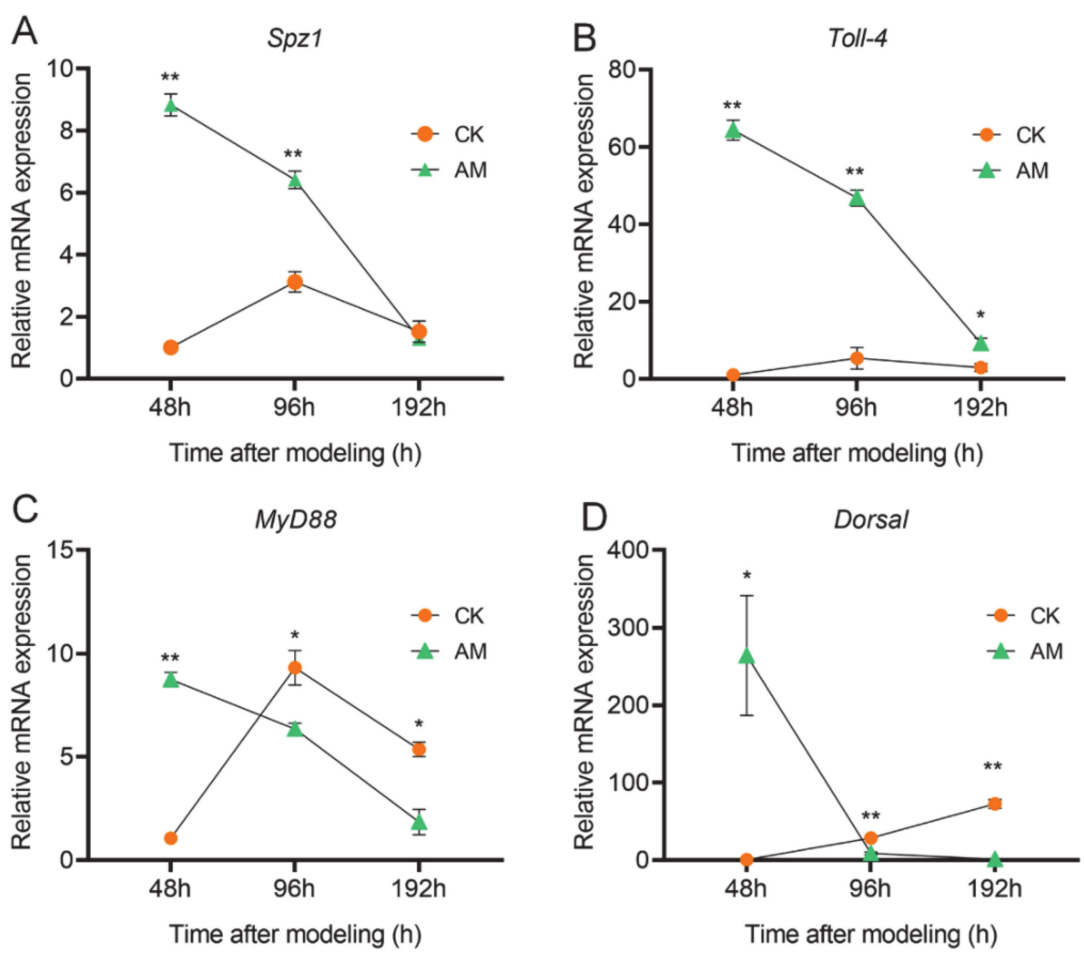

Figure 5. High PPC affected Toll signaling pathway genes expression. The mRNA levels of (A) Spz1 and (B) Toll-4 and (C) Myd88 and (D) Dorsal genes in hemocytes detected by qRT-PCR. * $p<0.05$; ** $p<0.01$. Mean \pm SEM. $n=3$.

Next, we investigated the changes in the level of PGRP-S2, Imd, Dredd, and Relish mRNA expression in the Imd pathway in the hemocytes (Figure S3). With the exception of Dredd, the transcription levels of the other three genes of the AM group, as well as changes in the trends during the period $48-192 \mathrm{~h}$ after modeling was significantly different from that of the CK group. Most of the experimental time points showed that high PPC induced upregulation of PGRP-S2, Imd, Dredd, and Relish (Figure S3A,B,D). Similar to the changes in the levels of gene transcription in the Toll pathway, PGRP-S2, Dredd, and Relish in the control group revealed a trend of first increasing followed by a decrease at 48, 96, and $192 \mathrm{~h}$ after modeling; however, the overall expression level was lower (Figure S3A,C,D). The significant difference in gene transcription of key members of the Toll and Imd pathways in the AM group suggests that high PPC has a greater impact on the Toll pathway associated with NF- $\mathrm{kB}$ signaling in hemocytes compared to the Imd pathway.

\subsection{High PPC Affects Hemolymph Melanization}

The aforementioned results presented in Figure 1 show that the proportion of Pla and Oen that produce phenoloxidase in the hemolymph of the AM group changed significantly. This finding implies that melanization plays an important role in the hemolymph immunity. Further investigation confirmed that the hemolymph of the AM group was naturally exposed to the environment in vitro, and the melanization rate was slower than that of control CK group (Figure 6A). It is speculated that the hemolymph of the AM group had a compensatory effect on the production of phenoloxidase though a significant decrease in Pla and increase in Oen. Next, we investigated the key enzymes involved in melanin production in the hemolymph. The phenoloxidase (PO) activity of the AM group was significantly lower than that of the CK group at $48-192 \mathrm{~h}$ after modeling. At $192 \mathrm{~h}$, the PO 
activity reached almost trace levels (Figure 6B). The PO activity of the CK group decreased for a short time at $96 \mathrm{~h}$, and was completely restored at $192 \mathrm{~h}$ after modeling.
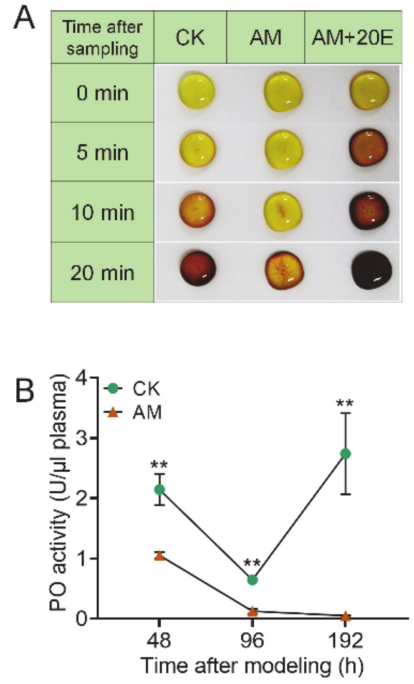
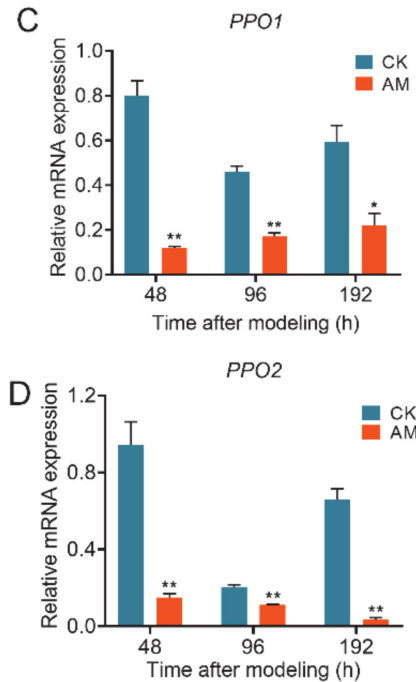

$\mathrm{E}$
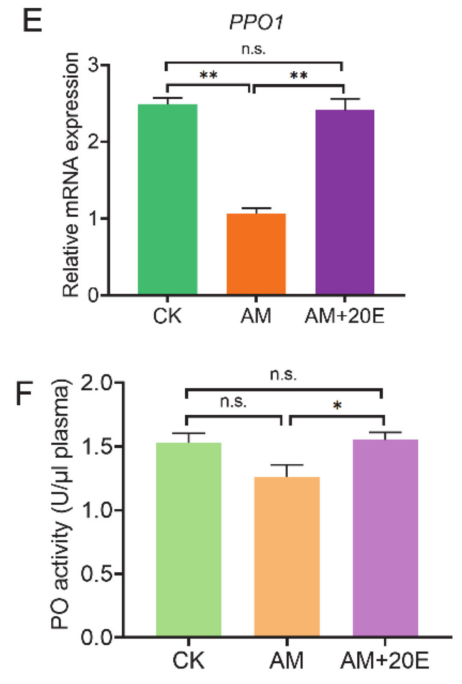

Figure 6. The melanization of hemolymph was inhibited by high PPC in silkworm after modeling and could be rescued by exogenous 20E. CK, the control group; AM, animal model of hyperproteinemia in which hyperproteinemia was induced at the wandering stage; $\mathrm{AM}+20 \mathrm{E}$, the larvae of the AM were rescued by injecting $4 \mu \mathrm{g}$ of $20 \mathrm{E}$ at $24 \mathrm{~h}$ after the induction of hyperproteinemia. (A) Melanization speed in vitro of hemolymph. (B) Phenoloxidase (PO) activity in hemolymph. (C,D) The mRNA levels of PPO1 and PPO2 in hemocytes. (E) The mRNA levels of PPO1 in hemocytes at $48 \mathrm{~h}$. (F) PO activity in hemolymph at $48 \mathrm{~h}$ after modeling. ${ }^{*} p<0.05 ;{ }^{* *} p<0.01 ;$ n.s., no significant difference between the two groups. Mean \pm SEM. $n=3$.

We understand that this observation is related to the increase in hemolymph immune consumption caused by the $\mathrm{FB}$ remodeling process at approximately $96 \mathrm{~h}$. The transcription levels of the two prophenoloxidase (PPO) genes in the hemocytes of $\mathrm{PO}$ protein synthesis tissue in hemolymph were investigated. Although the level of PPO1 and PPO2 mRNA expression was also downregulated with physiological remodeling of the FB in the CK group, the AM group at 48-192 h after modeling was always significantly lower than the CK group (Figure 6C,D). It shows that high PPC inhibits the activity of PO and weakens the melanization of hemolymph by downregulating the mRNA expression of PPO1 and PPO2.

Our previous research results showed that hyperproteinemia may weaken the $20 \mathrm{E}$ signaling pathway during silkworm metamorphic development [32]. To explore the relationship between the effect of high PPC on the silkworm hemolymph innate immune response and the endocrine system, we performed a rescue experiment of endocrine hormone $20 \mathrm{E}$ on the melanization induced by hyperproteinemia. At $24 \mathrm{~h}$ after the injection of $20 \mathrm{E}$ ( $48 \mathrm{~h}$ after modeling), the level of PPO1 mRNA expression and PO activity were restored to the level of the CK group (Figure 6E,F). The rate of hemolymph melanization in the 20E rescue group was significantly faster than that of the AM group, and even faster than that of the CK group (Figure 6A). This finding shows that the melanin effect induced by hyperproteinemia is weakened and can be effectively rescued by an exogenous supplementation with 20E.

To explain the weakening of hemolymph melanization in the AM group, we further investigated the content of serine, a representative metabolite of the serine protease cascade system that affects the initiation of insect innate immune responses, and the changes in the transcriptional activity of serine protease inhibitor (Serpins, Spns) genes and hemolymph protease (HPs) gene in hemocytes (Figure S4). Spns and Hps have an important effect on $\mathrm{PO}$ activity. In the $192 \mathrm{~h}$ experimental time period after modeling, the level of Spn5 gene transcription in the AM silkworm blood cells was higher than the control except at $96 \mathrm{~h}$, and the overall trend was significantly downregulated (Figure S4B). The level of Spn5 gene 
transcription was downregulated at $48 \mathrm{~h}$ and rebounded with an upregulation at $96 \mathrm{~h}$, which can be explained by a significant increase in the hemolymph serine content. The feedback regulation of recovery at $96 \mathrm{~h}$, but the downregulation of the level of Spn5 gene transcription at $192 \mathrm{~h}$ may be related to the complex effect of high PPC (Figure S4A,B). Investigation of the level of prophenoloxidase activating enzyme (PPAE) gene transcription in relation to the regulation of Spn27A transcription revealed that the decrease in hemolymph melanization ability is consistent with the change in the level of PPAE gene transcription induced by a high PPC environment (Figure S4C). The transcription level of another hemolymph protein $(H P)$ gene, which can affect the activity of PPO, was significantly higher than the control at $48 \mathrm{~h}$ after modeling; however, it was significantly lower than that of the control at 96 and $192 \mathrm{~h}$ (Figure S4D). This finding implies that there is a complex regulatory mechanism involved in the weakening of hemolymph melanization in the AM group.

\section{Discussion}

Abnormal metabolism of the circulatory system has a significant adverse effect on the immune system of mammals [53,54]; however, there remains a lack of reports on the effect of high PPC on the immune system in the circulatory system. It has been reported that hyperglycemia can induce the expression of Tolls in blood cells, inhibit neutrophil migration and apoptosis, as well as reduce its phagocytosis among other functions [53].

According to previously established methods [45], this study constructed a hyperproteinemia silkworm animal model (AM) and found that Gra and Oen in the circulating hemolymph of the AM increased significantly, whereas Pla was significantly reduced. High PPC also significantly affected the gene expression of the innate immune system, weakened melanization. In addition, the antibacterial activity of hemolymph against Gram-negative bacteria and positive bacteria has undergone inconsistent changes. These findings show that hyperproteinemia significantly affects the silkworm innate immune function and demonstrates the complexity of the pathway.

\subsection{High PPC Regulates Innate Immunity via the NF- $\kappa B$ Signaling Pathway}

In the bodily fluids of insects (e.g., silkworms), AMPs, antiviral factors, and agglutinin play an important role in immunity [55,56], and AMPs are the key substances involved in humoral immunity. AMPs found in insects primarily include Attacin, Cecropin, Defensin, Gloverin, Moricin, and Lebocin [57]. AMPs are mainly synthesized in the FB and hemocytes, followed by secretion into the hemolymph [58].

Studies have shown that the Toll and Imd pathways in insects and other animal cells are stimulated by microorganisms [32,39-41]. Peptidoglycan (PGN) recognition proteins (PGRPs) specifically activate the Toll pathway in response to lysine PGN (Lys-PGN) in most Gram-positive bacteria, and IMD pathway in response to diaminopimelic acid (DAP) PGN in Gram-positive bacteria and Gram-negative bacteria [59]. Reports of the relevant recognition mechanisms showed that peptidoglycan recognition protein S2 (PGRP-S2) is the main pattern recognition receptor of the Imd pathway. Immune stimulation is recognized by PGRP-S2, which activates Imd and Dredd in the membrane and in turn, regulates Relish transcription [60]. In the silkworm, the Fas-related factor, FAF, negatively regulates the Imd pathway and regulates antibacterial immunity by binding and degrading Relish [61]

Most AMPs in silkworm are activated by microbial stimuli. Cecropins are the most sensitive, exhibiting high levels of expression and antibacterial activity [62,63]. Among the antimicrobial peptides (AMPs) of silkworm, Attacin, Gloverin, and Lebocin only showed strong antibacterial activity against Gram-negative bacteria, while Cecropin, Moricin, and Defensin had inhibitory effects on both Gram-negative bacteria and Gram-positive bacteria $[55,57,64,65]$. Therefore, AMPs induced by high PPC significantly inhibited the growth of Gram-negative bacteria Escherichia coli (E. coli), but had little effect on Grampositive bacteria Staphylococcus aureus (S. aureus).

The results of this study show that high PPC induced the significant upregulation of the six $A M P$ s genes investigated in the fat body and hemocytes. We also found differences in 
the types of AMPs regulated by the Toll and Imd pathways. Further tests of the hemolymph antibacterial activity confirmed the presence of AM hemolymph that can significantly inhibit the Gram-negative bacteria, E. coli; however, this effect was not observed for the Gram-positive bacteria, S. aureus. This finding indicates that the difference in hemolymph antibacterial activity induced by high PPC against different pathogens may be related to AMP regulation via the Toll and Imd pathways in the immune response.

\subsection{High PPC Inhibits Hemolymph Melanization in Silkworm}

Humoral melanization is an important method of innate immunity in insects and other animals. In mutant fruit flies with low PO activity, a lower resistance to fungi, Grampositive, or Gram-negative bacteria, and significantly shorter life span was observed [34,37]. In the high PPC AM silkworm in this paper, the melanization ability of the hemolymph becomes weak, and the activity of the terminal rate-limiting enzyme, $\mathrm{PO}$, is significantly reduced in the melanin synthesis pathway. The level of mRNA transcription of the two encoding genes of the $\mathrm{PO}$ proenzyme, $P P O 1$ and $P P O 2$, are also significantly decreased. This finding shows that high PPC weakens melanization of the hemolymph by inhibiting melanin production. This finding is consistent with our previous report that the life span of the high PPC silkworm is significantly shorter [45]. Meanwhile, the results showed that high PPC decreased the number of plasmacytes and reduced the production of phenoloxidase, but the increase of Oen formed a compensation effect for the production of phenoloxidase. Therefore, it is also possible that what high PPC affected was just the number of hemocytes and it did not affect the signaling pathway for the phenoloxidase production in hemocytes.

Serine is a representative metabolite of the serine protease cascade system initiated by insect innate immune response, and the content of serine affects the changes of serine protease (Sp) and Serpins. Studies have shown that the serine protease cascade plays a key role in the initiation of the innate immune response, such as melanization and antimicrobial peptide production, and is strictly and precisely regulated by serine protease inhibitors (Serpins) [66]. The transcription of the two encoding genes of PPO, PPO1 and PPO2, are regulated by Serpins and HPs $[34,67,68]$. Serpin-5 (Spn5) of the Serpins family inhibits the silkworm blood and body melanization by inhibiting PPO activity [69]. Spn5 and Serpin-9 (Spn9) inhibit cSP4 and cSP6 activity of the clip-domain serine protease (cSP) family to prevent PPO activation, which inhibits melanization in the cotton bollworm [70]. Serpin27A (Spn27A) regulates the melanization cascade in Drosophila by specifically inhibiting PPAE activation of PPO [71]. In this study, in addition to the increase in serine content derived from silk protein in the early stage after modeling, the feedback regulation of Spns activity and the level of gene transcription during the content recovery process shows that the level of Spn5 and PPAE transcription in hemocytes was associated with a trend of downregulated expression. Furthermore, the level of hemolymph protease HP4 gene transcription was significantly downregulated $48 \mathrm{~h}$ after modeling. Together, these results show that high PPC leads to the downregulation of PPO anabolism in the hemolymph, including its feedback inhibition pathway-related Serpins and HPs and other transcription factors. This effect is a manifestation of reduced sensitivity to a high PPC response.

Previous studies have shown that melanization is closely related to the Toll pathway in NF-KB signaling. In the Drosophila PPO deletion mutants, $P P O 1^{\Delta}$ and $P P O 2^{\Delta}$, the lack of melanization specifically enhances Toll activation, despite the findings that PPO is not required for Toll and Imd pathway activation [37]. In the silkworm, knocking down the Toll ligand, Spätzle3 (Spz-3), reduced the deposition of epidermal melanin, whereas the ectopic expression of $5 p z-3$ induced the deposition of epidermal melanin [72]. Since NF-kB signaling is highly conserved in both insects and mammals [73-75], it is implied that the high PPC in the silkworm model in relation to NF- $\mathrm{kB}$ signaling may have a broader significance for melanization. In the present study, the level of $S p z-1$ transcription in the Toll pathway in the hemocytes increased during the initial $48 \mathrm{~h}$ after modeling, and significantly decreased thereafter. However, our previous research results showed that the blackening 
of the epidermis of the high PPC silkworm was significantly more severe than the control after $96 \mathrm{~h}$ of modeling [45]. This suggests that the weakening effect of high PPC on the melanization in the hemolymph of silkworm may be related to enhanced melanization of the epidermis during the same period.

\section{Conclusions}

High PPC has multiple significant effects on innate immune function via changes in the composition of the hemocytes, inhibition of hemolymph melanization, differential activation of the Toll and Imd pathways in NF-kB signaling (Figure 7).

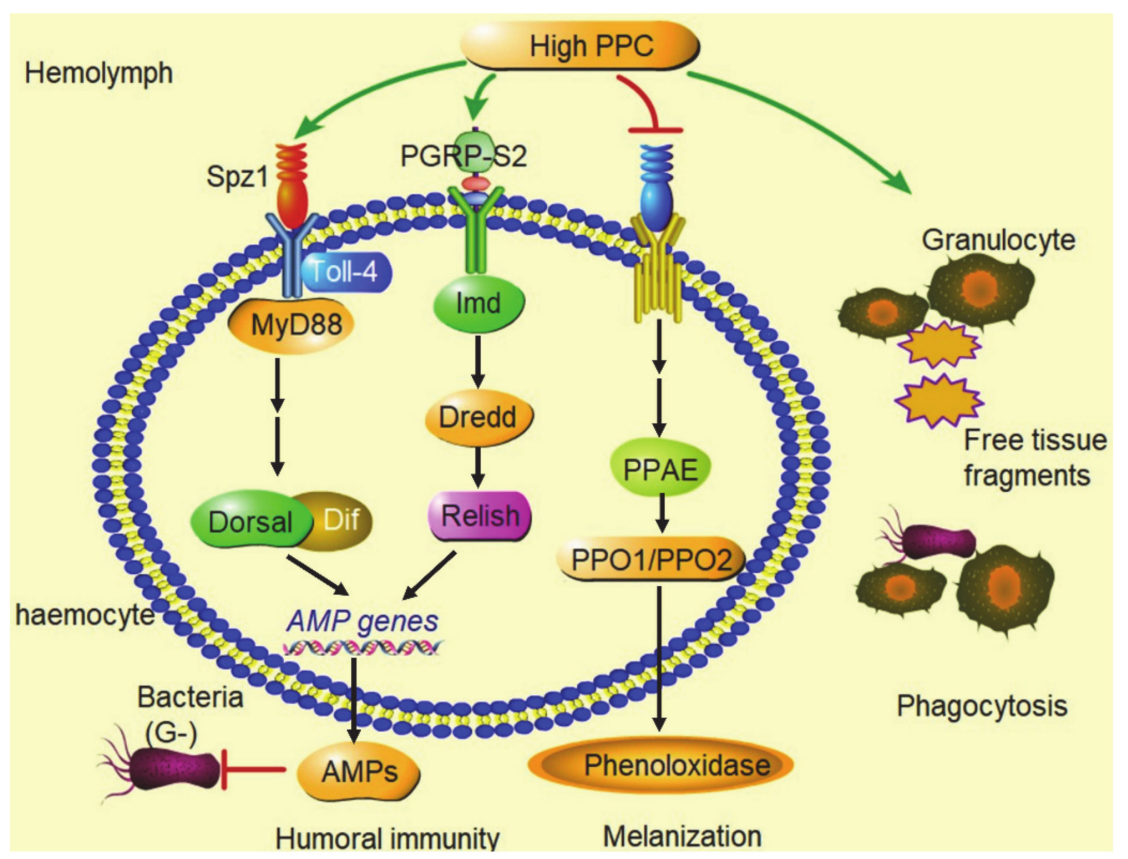

Figure 7. Summary graph. High PPC inhibited phenoloxidase production and melanization of hemolymph in silkworm; high PPC induced granulocytes to phagocytize free tissue fragments in hemolymph, such as dissociated fat body cells; high PPC activated the Toll pathway and Imd pathway in NF-kB signaling, and promoted the large expression of AMPs genes.

Supplementary Materials: The following are available online at https:/ / www.mdpi.com/2079-773 7/10/2/112/s1, Figure S1: The proportion of hemocytes in hemolymph of silkworm after modeling. Pro, prohemocyte; Pla, plasmacyte; Gra, granulocyte; Sph, spherulocyte; Oen, oenocytoid. Figure S2: Antibacterial activity of high PPC silkworm cell-free hemolymph. The hemolymph of the silkworm was collected for heat treatment at 48 and $96 \mathrm{~h}$ after modeling, and the supernatant was cocultured with E. coli and $S$. aureus, and the growth of E. coli (A,B) and $S$. aureus (C,D) was investigated. ${ }^{*} p<0.05$; ${ }^{* *} p<0.01$; Mean \pm SEM. $n=3$. Figure S3: High PPC induces Imd signaling pathway. The mRNA levels of (A) PGRP-S2 and (B) Imd and (C) Dredd and (D) Relish genes in hemocytes detected by qRT-PCR. ${ }^{*} p<0.05 ;{ }^{* *} p<0.01$. Mean \pm SEM. $n=3$. Figure S4: High PPC affects the melanization of hemolymph in silkworm. (A) Relative content of Serine in hemolymph at 48 and $96 \mathrm{~h}$ after modeling. Serine content was determined by GC-MS method. (B-D) the mRNA levels of Spn5, HP14, and PPAE in hemocytes after modeling. ${ }^{*} p<0.05$; ${ }^{* *} p<0.01$; n.s., no significant difference between the two groups. Mean \pm SEM. $n=3$. Table S1: qPCR primers used in this part. Table S2: Differential expressed genes of Toll and Imd signaling pathway at $96 \mathrm{~h}$.

Author Contributions: Conceptualization, S.-Q.X., Y.-F.W. and G.W.; methodology, S.-Q.X., Y.-F.W. and G.W.; investigation, Y.-F.W., G.W., J.-L.L., Y.-X.Q., X.-Y.L. and X.-D.C.; data curation, Y.-F.W.; writing - original draft preparation, Y.-F.W.; writing—review and editing, S.-Q.X. and Y.-F.W.; funding acquisition, S.-Q.X., Y.-F.W., Y.-H.S. and G.W. All authors have read and agreed to the published version of the manuscript. 
Funding: This research was funded by the National Natural Science Foundation of China, grant number 31972625; China Postdoctoral Science Foundation, grant number 2020M681718; A Project Funded by the Priority Academic Program Development of Jiangsu Higher Education Institutions (PAPD); the Postgraduate Research and Practice Innovation Program of Jiangsu Province (KYCX20_2674), and the China Agriculture Research System (CARS).

Institutional Review Board Statement: Ethical review and approval were waived for this study, due to silkworm did not have ethical issues.

Informed Consent Statement: Not applicable.

Data Availability Statement: The data presented in this study are available on request from the corresponding author.

Acknowledgments: The manuscript was edited by a native English speaker of International Science Editing Scientific Services.

Conflicts of Interest: The authors declare no conflict of interest. The funders had no role in the design of the study; in the collection, analyses, or interpretation of data; in the writing of the manuscript, or in the decision to publish the results.

\section{References}

1. Singer, C.E.; Neagoe, D.; Coşoveanu, S.; Puiu, I.; Oancea, G. Severe Toxocariasis in Children-Diagnostic Difficulties. Curr. Health Sci. J. 2016, 42, 413-416. [PubMed]

2. Meléndez-Lazo, A.; Ordeix, L.; Planellas, M.; Pastor, J.; Solano-Gallego, L. Clinicopathological findings in sick dogs naturally infected with Leishmania infantum: Comparison of five different clinical classification systems. Res. Veter Sci. 2018, 117, 18-27. [CrossRef] [PubMed]

3. Perondi, F.; Brovida, C.; Ceccherini, G.; Guidi, G.; Lippi, I. Double filtration plasmapheresis in the treatment of hyperproteinemia in dogs affected by Leishmania infantum. J. Veter Sci. 2018, 19, 472-476. [CrossRef] [PubMed]

4. Hussain, A.; Almenfi, H.F.; Almehdewi, A.M.; Hamza, M.S.; Bhat, M.S.; Vijayashankar, N.P. Laboratory Features of Newly Diagnosed Multiple Myeloma Patients. Cureus 2019, 11, e4716. [CrossRef] [PubMed]

5. Kluck, G.E.G.; Wendt, C.H.C.; Imperio, G.E.D.; Araujo, M.F.C.; Atella, T.C.; Da Rocha, I.; Miranda, K.R.; Atella, G.C. Plasmodium Infection Induces Dyslipidemia and a Hepatic Lipogenic State in the Host through the Inhibition of the AMPK-ACC Pathway. Sci. Rep. 2019, 9, 1-13. [CrossRef] [PubMed]

6. Takeuchi, Y.; Iizuka, H.; Kanemitsu, H.; Fujino, Y.; Nakashima, K.; Uchida, K.; Ohno, K.; Nakayama, H.; Tsujimoto, H. Myelomarelated disorder with leukaemic progression in a cat. J. Feline Med. Surg. 2010, 12, 982-987. [CrossRef]

7. Salvesen, H.A. Hyperproteinemia in a Case of Nephrosis.1. J. Intern. Med. 2010, 65, 152-159. [CrossRef]

8. Kitazawa, A.; Koda, R.; Yoshino, A.; Ueda, Y.; Takeda, T. An IgA1-lambda-type monoclonal immunoglobulin deposition disease associated with membranous features in a patient with IgG4-related kidney disease: A case report. BMC Nephrol. 2018, 19, 1-7. [CrossRef]

9. Matoušek, V.; Herold, I.; Holanová, L.; Balik, M. A Rare Case of Severe Metabolic Alkalosis with Unusual Hyperproteinemia Treated with Continuous Renal Replacement Therapy and Regional Citrate Anticoagulation. Case Rep. Nephrol. Dial. 2018, 8, 138-146. [CrossRef]

10. Oliveira, V.D.C.; Junior, A.A.V.M.; Cavalcanti, M.C.D.H.; Madeira, M.D.F.; Ferreira, L.C.; Figueiredo, F.B.; De Campos, M.P.; Nadal, N.V.; Almosny, N.R.P.; Menezes, R. First description of parasite load and clinicopathological and anatomopathological changes in a dog naturally coinfected with Dioctophyme renale and Leishmania infantum in Brazil. Veter Parasitol. Reg. Stud. Rep. 2019, 18, 100351. [CrossRef]

11. Bergstedt, J.; Lingen, C. Cirrhosis of the Liver in Two Children with Hyperproteinaemia. Acta Paediatr. 1957, 46, 185-190. [CrossRef] [PubMed]

12. Eberhardt, C.; Malbon, A.; Riond, B.; Schoster, A. $\mathrm{k}$ Light-chain monoclonal gammopathy and cast nephropathy in a horse with multiple myeloma. J. Am. Veter Med. Assoc. 2018, 253, 1177-1183. [CrossRef] [PubMed]

13. Adeyeba, O.A. Hyperproteinaemia in dracunculiasis. Int. J. Zoonoses 1985, 12, 150-151. [PubMed]

14. Wang, F.; Butler, T.; Rabbani, G.; Jones, P.K. The Acidosis of Cholera. New Engl. J. Med. 1986, 315, 1591-1595. [CrossRef]

15. Ogborn, M.R.; Crocker, J.F.; Barnard, D.R. Plasma therapy for severe hemolytic-uremic syndrome in children in Atlantic Canada. CMAJ 1990, 143, 1323-1326. [CrossRef]

16. Boyle, T.E.; Holowaychuk, M.K.; Adams, A.K.; Marks, S.L. Treatment of Three Cats with Hyperviscosity Syndrome and Congestive Heart Failure Using Plasmapheresis. J. Am. Anim. Hosp. Assoc. 2011, 47, 50-55. [CrossRef]

17. Thielen, L.A.; Chen, J.; Jing, G.; Moukha-Chafiq, O.; Xu, G.; Jo, S.; Grayson, T.B.; Lu, B.; Li, P.; Augelli-Szafran, C.E.; et al. Identification of an Anti-diabetic, Orally Available Small Molecule that Regulates TXNIP Expression and Glucagon Action. Cell. Metab. 2020, 32, 353-365. [CrossRef] 
18. Manzoni, A.G.; Passos, D.F.; Doleski, P.H.; Leitemperger, J.W.; Loro, V.L.; Leal, D.B.R. Purine Metabolism in Platelets and Heart Cells of Hyperlipidemic Rats. Cardiovasc. Drugs Ther. 2020, 34, 813-821. [CrossRef]

19. McCrindle, B.W.; Gidding, S.S. What Should Be the Screening Strategy for Familial Hypercholesterolemia? N. Engl. J. Med. 2016, 375, 1685-1686. [CrossRef]

20. Cicero, A.F.G.; Fogacci, F.; Hernandez, A.V.; Banach, M.; on behalf of the Lipid and Blood Pressure Meta-Analysis Collaboration (LBPMC) Group and the International Lipid Expert Panel (ILEP). Efficacy and safety of bempedoic acid for the treatment of hypercholesterolemia: A systematic review and meta-analysis. PLoS Med. 2020, 17, e1003121. [CrossRef]

21. Ponticelli, C.; Podestà, M.A.; Moroni, G. Hyperuricemia as a trigger of immune response in hypertension and chronic kidney disease. Kidney. Int. 2020, 98, 1149-1159. [CrossRef] [PubMed]

22. Aslam, M.W.; Lau, S.F.; Chin, C.S.L.; Ahmad, N.I.; Rahman, N.-A.; Kuppusamy, K.; Omar, S.; Radzi, R. Clinicopathological and radiographic features in 40 cats diagnosed with pulmonary and cutaneous Rhodococcus equi infection (2012-2018). J. Feline Med. Surg. 2019, 22, 774-790. [CrossRef] [PubMed]

23. Weidmann, H.; Heikaus, L.; Long, A.T.; Naudin, C.; Schlüter, H.; Renné, T. The plasma contact system, a protease cascade at the nexus of inflammation, coagulation and immunity. Biochim. Biophys. Acta Bioenerg. 2017, 1864, 2118-2127. [CrossRef] [PubMed]

24. McDonald, B.; Dunbar, M. Platelets and Intravascular Immunity: Guardians of the Vascular Space during Bloodstream Infections and Sepsis. Front. Immunol. 2019, 10, 2400. [CrossRef] [PubMed]

25. Wójcik, P.; Biernacki, M.; Wroński, A.; Łuczaj, W.; Waeg, G.; Zarković, N.; Skrzydlewska, E. Altered Lipid Metabolism in Blood Mononuclear Cells of Psoriatic Patients Indicates Differential Changes in Psoriasis Vulgaris and Psoriatic Arthritis. Int. J. Mol. Sci. 2019, 20, 4249. [CrossRef] [PubMed]

26. Nagy, T.; Fisi, V.; Frank, D.; Kátai, E.; Nagy, Z.; Miseta, A. Hyperglycemia-Induced Aberrant Cell Proliferation; A Metabolic Challenge Mediated by Protein O-GlcNAc Modification. Cells 2019, 8, 999. [CrossRef] [PubMed]

27. Duan, Q.; Li, H.; Gao, C.; Zhao, H.; Wu, S.; Wu, H.; Wang, C.; Shen, Q.; Yin, T. High glucose promotes pancreatic cancer cells to escape from immune surveillance via AMPK-Bmi1-GATA2-MICA/B pathway. J. Exp. Clin. Cancer Res. 2019, 38, 1-13. [CrossRef] [PubMed]

28. Biswas, S.; Zimman, A.; Gao, D.; Byzova, T.V.; Podrez, E.A. TLR2 Plays a Key Role in Platelet Hyperreactivity and Accelerated Thrombosis Associated With Hyperlipidemia. Circ. Res. 2017, 121, 951-962. [CrossRef]

29. Proto, J.D.; Doran, A.C.; Subramanian, M.; Wang, H.; Zhang, M.; Sozen, E.; Rymond, C.C.; Kuriakose, G.; D'Agati, V.; Winchester, R.; et al. Hypercholesterolemia induces T cell expansion in humanized immune mice. J. Clin. Investig. 2018, 128, $2370-2375$. [CrossRef]

30. Mailer, R.K.; Gisterå, A.; Polyzos, K.A.; Ketelhuth, D.F.; Hansson, G.K. Hypercholesterolemia Induces Differentiation of Regulatory T Cells in the Liver. Circ. Res. 2017, 120, 1740-1753. [CrossRef]

31. Tall, A.R.; Yvan-Charvet, L. Cholesterol, inflammation and innate immunity. Nat. Rev. Immunol. 2015, 15, 104-116. [CrossRef] [PubMed]

32. Tzou, P. How Drosophila combats microbial infection: A model to study innate immunity and host-pathogen interactions. Curr. Opin. Microbiol. 2002, 5, 102-110. [CrossRef]

33. Strand, M.R. The insect cellular immune response. Insect Sci. 2008, 15, 1-14. [CrossRef]

34. Lu, A.; Zhang, Q.; Zhang, J.; Yang, B.; Wu, K.; Xie, W.; Luan, Y.-X.; Ling, E. Insect prophenoloxidase: The view beyond immunity. Front. Physiol. 2014, 5, 252. [CrossRef] [PubMed]

35. Chen, K.; Lu, Z. Immune responses to bacterial and fungal infections in the silkworm, Bombyx mori. Dev. Comp. Immunol. 2018, 83, 3-11. [CrossRef] [PubMed]

36. Cerenius, L.; Lee, B.L.; Söderhäll, K. The proPO-system: Pros and cons for its role in invertebrate immunity. Trends Immunol. 2008, 29, 263-271. [CrossRef] [PubMed]

37. Binggeli, O.; Neyen, C.; Poidevin, M.; Lemaitre, B. Prophenoloxidase Activation Is Required for Survival to Microbial Infections in Drosophila. PLoS Pathog. 2014, 10, e1004067. [CrossRef]

38. Banerjee, U.; Girard, J.R.; Goins, L.M.; Spratford, C.M. Drosophila as a genetic model for hematopoiesis. Genetics 2019, 211, 367-417. [CrossRef]

39. De Gregorio, E.; Spellman, P.T.; Tzou, P.; Rubin, G.M.; Lemaitre, B. The Toll and Imd pathways are the major regulators of the immune response in Drosophila. EMBO J. 2002, 21, 2568-2579. [CrossRef]

40. Hoffmann, J.A.; Reichhart, J.-M. Drosophila innate immunity: An evolutionary perspective. Nat. Immunol. 2002, 3, 121-126. [CrossRef]

41. Chowdhury, M.; Li, C.-F.; He, Z.; Lu, Y.; Liu, X.-S.; Wang, Y.-F.; Ip, Y.T.; Strand, M.R.; Yu, X.-Q. Toll family members bind multiple Spätzle proteins and activate antimicrobial peptide gene expression in Drosophila. J. Biol. Chem. 2019, 294, 10172-10181. [CrossRef]

42. Valanne, S.; Wang, J.-H.; Rämet, M. The Drosophila Toll Signaling Pathway. J. Immunol. 2011, 186, 649-656. [CrossRef] [PubMed]

43. Myllymäki, H.; Valanne, S.; Rämet, M. The Drosophila Imd Signaling Pathway. J. Immunol. 2014, 192, 3455-3462. [CrossRef] [PubMed]

44. Hillyer, J.F. Insect immunology and hematopoiesis. Dev. Comp. Immunol. 2016, 58, 102-118. [CrossRef] [PubMed]

45. Chen, X.-D.; Wang, Y.-F.; Wang, Y.-L.; Li, Q.-Y.; Ma, H.-Y.; Wang, L.; Sima, Y.-H.; Xu, S.-Q. Induced Hyperproteinemia and Its Effects on the Remodeling of Fat Bodies in Silkworm, Bombyx mori. Front. Physiol. 2018, 9, 302. [CrossRef] [PubMed] 
46. Wang, Y.-F.; Chen, X.-D.; Wang, G.; Li, Q.-Y.; Liang, X.-Y.; Sima, Y.-H.; Xu, S.-Q. Influence of hyperproteinemia on reproductive development in an invertebrate model. Int. J. Biol. Sci. 2019, 15, 2170-2181. [CrossRef]

47. Magid, J.H. Chronic Hyperproteinemia Associated with a Probable Abdominal Abscess in an Appaloosa Stallion. Veter- Clin. N. Am. Equine Pr. 2006, 22, 53-60. [CrossRef]

48. Riemer, F.; Kuehner, K.A.; Ritz, S.; Sauter-Louis, C.; Hartmann, K. Clinical and laboratory features of cats with feline infectious peritonitis-A retrospective study of 231 confirmed cases (2000-2010). J. Feline Med. Surg. 2016, 18, 348-356. [CrossRef]

49. He, Y.; Xu, X.; Qiu, J.; Yin, W.; Sima, Y.; Xu, S.-Q. Bombyx mori used as a fast detection model of liver melanization after a clinical drug-Acetaminophen exposure. J. Asia Pacific Éntomol. 2020, 23, 177-185. [CrossRef]

50. Zhang, J.; Yang, W.; Xu, J.; Yang, W.; Li, Q.; Zhong, Y.; Cao, Y.; Yu, X.-Q.; Deng, X. Regulation of antimicrobial peptide genes via insulin-like signaling pathway in the silkworm Bombyx mori. Insect Biochem. Mol. Biol. 2018, 103, 12-21. [CrossRef]

51. Barger, S.R.; Gauthier, N.C.; Krendel, M. Squeezing in a Meal: Myosin Functions in Phagocytosis. Trends. Cell. Biol. 2020, 30, 157-167. [CrossRef] [PubMed]

52. Flannagan, R.S.; Harrison, R.E.; Yip, C.M.; Jaqaman, K.; Grinstein, S. Dynamic macrophage "probing" is required for the efficient capture of phagocytic targets. J. Cell Biol. 2010, 191, 1205-1218. [CrossRef] [PubMed]

53. Jafar, N.; Edriss, H.; Nugent, K. The Effect of Short-Term Hyperglycemia on the Innate Immune System. Am. J. Med. Sci. 2016, 351, 201-211. [CrossRef] [PubMed]

54. Kritikou, E.; Van Der Heijden, T.; Swart, M.; Van Duijn, J.; Slütter, B.; Wezel, A.; Smeets, H.J.; Maffia, P.; Kuiper, J.; Bot, I. Hypercholesterolemia Induces a Mast Cell-CD4+ T Cell Interaction in Atherosclerosis. J. Immunol. 2019, 202, 1531-1539. [CrossRef]

55. Wu, Q.; Patočka, J.; Kuča, K. Insect antimicrobial peptides, a mini review. Toxins 2018, 10, 461. [CrossRef]

56. Lu, Y.; Su, F.; Li, Q.; Zhang, J.; Li, Y.; Tang, T.; Hu, Q.; Yu, X.-Q. Pattern recognition receptors in Drosophila immune responses. Dev. Comp. Immunol. 2020, 102, 103468. [CrossRef]

57. Yi, H.-Y.; Chowdhury, M.; Huang, Y.-D.; Yu, X.-Q. Insect antimicrobial peptides and their applications. Appl. Microbiol. Biotechnol. 2014, 98, 5807-5822. [CrossRef]

58. Hetru, C.; Hoffmann, J.A. NF- B in the Immune Response of Drosophila. Cold Spring Harb. Perspect. Biol. 2009, 1, a000232. [CrossRef]

59. Zaidman-Rémy, A.; Poidevin, M.; Hervé, M.; Welchman, D.P.; Paredes, J.C.; Fahlander, C.; Steiner, H.; Mengin-Lecreulx, D.; Lemaitre, B. Drosophila Immunity: Analysis of PGRP-SB1 Expression, Enzymatic Activity and Function. PLoS ONE 2011, 6, e17231. [CrossRef]

60. Zhao, P.; Xia, F.; Jiang, L.; Guo, H.; Xu, G.; Sun, Q.; Wang, B.; Wang, Y.; Lu, Z.; Xia, Q. Enhanced antiviral immunity against Bombyx mori cytoplasmic polyhedrosis virus via overexpression of peptidoglycan recognition protein S2 in transgenic silkworms. Dev. Comp. Immunol. 2018, 87, 84-89. [CrossRef]

61. Ma, X.; Li, X.; Dong, S.; Xia, Q.; Wang, F. A Fas associated factor negatively regulates anti-bacterial immunity by promoting Relish degradation in Bombyx mori. Insect Biochem. Mol. Biol. 2015, 63, 144-151. [CrossRef] [PubMed]

62. Tanaka, H.; Yamamoto, M.; Moriyama, Y.; Yamao, M.; Furukawa, S.; Sagisaka, A.; Nakazawa, H.; Mori, H.; Yamakawa, M. A novel Rel protein and shortened isoform that differentially regulate antibacterial peptide genes in the silkworm Bombyx mori. Biochim. Biophys. Acta. 2005, 1730, 10-21. [CrossRef] [PubMed]

63. Tanaka, H.; Yamakawa, M. Regulation of the innate immune responses in the silkworm, Bombyx mori. ISJ-Invert. Surviv. J. 2011, 8, $59-69$.

64. Furukawa, S.; Tanaka, H.; Nakazawa, H.; Ishibashi, J.; Shono, T.; Yamakawa, M. Inducible gene expression of moricin, a unique antibacterial peptide from the silkworm (Bombyx mori). Biochem. J. 1999, 340. [CrossRef]

65. Tanaka, H.; Sagisaka, A.; Fujita, K.; Furukawa, S.; Ishibashi, J.; Yamakawa, M. BmEts upregulates promoter activity of lebocin in Bombyx mori. Insect Biochem. Mol. Biol. 2012, 42, 474-481. [CrossRef]

66. Shakeel, M.; Xu, X.; De Mandal, S.; Jin, F. Role of serine protease inhibitors in insect-host-pathogen interactions. Arch. Insect Biochem. Physiol. 2019, 102, e21556. [CrossRef]

67. Waterhouse, R.M.; Kriventseva, E.V.; Meister, S.; Xi, Z.; Alvarez, K.S.; Bartholomay, L.C.; Barillas-Mury, C.; Bian, G.; Blandin, S.; Christensen, B.M.; et al. Evolutionary Dynamics of Immune-Related Genes and Pathways in Disease-Vector Mosquitoes. Science 2007, 316, 1738-1743. [CrossRef]

68. Cooper, D.; Wuebbolt, C.; Heryanto, C.; Eleftherianos, I. The prophenoloxidase system in Drosophila participates in the antinematode immune response. Mol. Immunol. 2019, 109, 88-98. [CrossRef]

69. Li, J.; Ma, L.; Lin, Z.; Zou, Z.; Lu, Z. Serpin-5 regulates prophenoloxidase activation and antimicrobial peptide pathways in the silkworm, Bombyx mori. Insect Biochem. Mol. Biol. 2016, 73, 27-37. [CrossRef]

70. Yuan, C.; Xing, L.; Wang, M.; Wang, X.; Yin, M.; Wang, Q.; Hu, Z.; Zou, Z. Inhibition of melanization by serpin-5 and serpin-9 promotes baculovirus infection in cotton bollworm Helicoverpa armigera. PLoS. Pathog. 2017, 13, e1006645. [CrossRef]

71. De Gregorio, E.; Han, S.-J.; Lee, W.-J.; Baek, M.-J.; Osaki, T.; Kawabata, S.-I.; Lee, B.-L.; Iwanaga, S.; Lemaitre, B.; Brey, P.T. An Immune-Responsive Serpin Regulates the Melanization Cascade in Drosophila. Dev. Cell. 2002, 3, 581-592. [CrossRef]

72. Kondo, Y.; Yoda, S.; Mizoguchi, T.; Ando, T.; Yamaguchi, J.; Yamamoto, K.; Banno, Y.; Fujiwara, H. Toll ligand Spätzle3 controls melanization in the stripe pattern formation in caterpillars. Proc. Natl. Acad. Sci. USA 2017, 114, 8336-8341. [CrossRef] 
73. Senftleben, U.; Cao, Y.; Xiao, G.; Greten, F.R.; Krähn, G.; Bonizzi, G.; Chen, Y.; Hu, Y.; Fong, A.; Sun, S.-C.; et al. Activation by IKKalpha of a Second, Evolutionary Conserved, NF-kappa B Signaling Pathway. Science 2001, 293, 1495-1499. [CrossRef] [PubMed]

74. Van Uden, P.; Kenneth, N.S.; Webster, R.; Müller, H.A.; Mudie, S.; Rocha, S. Evolutionary Conserved Regulation of HIF-1 $\beta$ by NF-кB. PLoS Genet. 2011, 7, e1001285. [CrossRef] [PubMed]

75. Brennan, J.J.; Gilmore, T.D. Evolutionary Origins of Toll-like Receptor Signaling. Mol. Biol. Evol. 2018, 35, 1576-1587. [CrossRef] 